Research Paper:

\title{
Evaluation of Students' Awareness of Charter of Patients' Rights
}

Hadis Ashrafizadeh" (D), Mahmood Maniati² (D), Mohammad Adineh ${ }^{3^{*}}$ (D), Nasrin Elahi ${ }^{3}$ (D), Shahram Molavynejad ${ }^{3}$, Safa Najafi $^{4}$ (D)

1. Student Research Committee, School of Nursing and Midwifery, Ahvaz Jundishapur University of Medical Sciences, Ahvaz, Iran

2. School of Medicine, Ahvaz Jundishapur University of Medical Sciences, Ahvaz, Iran

3. Nursing Care Research Center in Chronic Disease, School of Nursing and Midwifery, Ahvaz Jundishapur University of Medical Sciences, Ahvaz, Iran.

4. School of Nursing and Midwifery, Ahvaz Jundishapur University of Medical Sciences, Ahvaz, Iran.

\begin{tabular}{|l|l|}
$\begin{array}{l}\text { Use vour device to scan } \\
\text { and read the article online }\end{array}$ & $\begin{array}{l}\text { Clteation: Ashrafizadeh, H., et al. 2019. Evaluation of Students' Awareness of Charter of Patients' Rights. Journal of Client- } \\
\text { Centered Nursing Care, 5(4), pp. 269-276. https://doi.org/10.32598/JCCNC.5.4.238.1 }\end{array}$ \\
dol'https://doi.org/10.32598/JCCNC.5.4.238.1
\end{tabular}

\section{(c) (i) (\$)}

Article info:

Received: 20 Apr 2019

Accepted: 25 Aug 2019

Published: 01 Nov 2019

Keywords:

Charter of Patients' Rights, Senior medical students, Clinical, Awareness

\begin{abstract}
A B S T RA C T
Background: As an essential principle, the collective life of human beings can constitute a human society only when human rights are respected. Demanding and respecting the rights of patients, as an inevitable part of human society, requires familiarity with patient-involved individuals. The present study aimed to determine the awareness level of Ahvaz Jundishapur University of Medical Sciences (AJUMS) students about the Charter of Patients' Rights (CPR).

Methods: This descriptive-analytical study was conducted on 200 senior university students who had been in contact with patients during their undergraduate program. They were invited from different faculties of the university. The data collection tool was a two-section questionnaire. The first section covered the demographic information, and the second included 29 questions about the 5 principles of the CPR. The obtained data were analyzed in SPSS by descriptive statistics, and analytical tests, including Independent Samples t-test, Analysis of Variance (ANOVA), and Spearman's correlation coefficient.
\end{abstract}

Results: From the 200 study participants, 103 (51\%) were female. The Mean \pm SD of students awareness was $14.50 \pm 2.3$. The highest and lowest mean scores belonged to the areas of access to services and confidentiality. There was no statistically significant difference between the awareness score of students from different faculties $(\mathrm{P}=0.359)$.

Conclusion: This study results suggested that the awareness level of the medical students about the CPR was unsatisfactory. Instituting ethical codes among students and providing them knowledge of their professional lives is an essential part of the university's responsibilities.

\section{* Corresponding Author:}




\section{Highlights}

- Charter of Patients' Rights is considered as a common standard for achieving the realization of this right.

- Respecting the rights of patients, as an inevitable part of human society is crucial for quality care.

- The awareness level of medical students about the patients' rights is of significant importance.

\section{Plain Language Summary}

According to the CPR, it is the patient's right to receive confidential care and to request accurate information. The purpose of the patient right charter is to defend human rights to preserve their dignity. Since students are directly in contact with patients during their internship in hospitals, it is necessary to respect patients' rights as part of their care. This study evaluated the awareness level of Ahvaz Jundishapur University of Medical Sciences students on patient's clinical rights. The study findings revealed that the awareness level of the medical students about the CPR is unsatisfactory. Moreover, there was no significant difference between the awareness score of students from different faculties.

\section{Introduction}

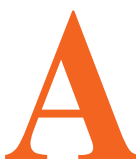

$\mathrm{s}$ an essential principle, the collective life of human beings can only constitute a human society when human rights are respected (Parsapoor, Salari \& Larijani 2013). The health systems of different countries are essentially influential in promoting the individuals' health quality and developing a Charter of Patients' Rights (CPR); it is a critical approach to provide patients with their required healthcare information (Parsapoor, Salari \& Larijani 2013; Babamahmoodi et al. 2011; Kuzu, Ergin \& Zencir 2006; Mastaneh \& Mouseli 2013; Jolaee, Nikbakht Nasrabadi \& Parsa Yekta 2005; Parsapour et al. 2009). The issue of patient rights has received much attention in the last two decades (Bateni, Sajadi \& Hoseini 2011).

Patients' rights are defined as the expectations that patients have from healthcare facilities. The patient's position in the mental-value system of healthcare providers has a great impact on how to observe ethics (Joolaee \& Hajibabaee 2012). According to the CPR, it is the patient's right to receive confidential care to request accurate information from physicians and other caregivers about the disease diagnosis, treatment, and prognosis, and to make a decision on the continuation or termination of treatment. The purpose of the CPR includes the following points: defending human rights to preserve their dignity and to ensure that in case of illness, especially in medical emergencies, they will be protected and receive medical attention regardless of their race, age, gender, and socioeconomic class (Vaskooei Eshkevari et al. 2009).
Most countries have developed a CPR, provided it to executive bodies, and supported its implementation (Parsapoor, Salari \& Larijani 2013; Babamahmoodi et al. 2011). According to Article 29 of the Iranian Constitution, the Iranian Ministry of Health and Medical Education has drafted the Charter of Patients' Rights in 2002 following the WHO Charter, published it, and has notified all health centers about it. All centers are required to install the CPR in the right place to ensure that the patients are aware of their rights, claim their rights, take care of themselves, and are informed of their treatment process. This will improve community health and reduce the workload of medical professionals and medical staff (Parsapoor, Salari \& Larijani 2013; Babamahmoodi et al. 2011). Since the drafting and notification of the charter cannot necessarily guaranty its implementation, it is necessary to evaluate its compliance.

Numerous studies have been conducted in Iran and overseas to assess the extent to which patients' rights are respected (Babamahmoodi et al. 2011; Parsapour et al. 2009; Hooshmand et al. 2007; Özdemir et al. 2009; Arab \& Zarei 2009; Yaghobian et al. 2014). Hooshmand et al. (2007), for example, studied nurses' awareness of patients' rights; they concluded that nurses had moderate knowledge about the patient's rights to receive personal information in the stages of disease diagnosis, treatment, and progression (Hooshmand et al. 2007). Arab \& Zarei (2009) assessed hospital managers' awareness of patients' rights in public and private hospitals in Tehran City, Iran. They concluded that $34.5 \%, 48.5 \%$, and $17 \%$ of the public hospitals' managers in Tehran respectively had good, moderate, and poor knowledge about patients' rights. Ad- 
ditionally, academic degree, the field of study, and receiving management courses were influential factors on the managers' awareness of patients' rights (Arab \& Zarei 2009). In a survey conducted in Yazd, a desirable level of personnel awareness of patients' rights was reported (Joolaee \& Hajibabaee 2012). Other evidence suggests that patients' understanding of their rights is below average (Zandiyeh et al. 2015). Furthermore, in the patients' view, the provisions of this charter have not been met by nurses, physicians, and other healthcare professionals despite their knowledge (Larijani, Ghafourifard \& Zahedi 2005).

Failure to respect patients' rights and their dissatisfaction with the provided services result in slow recovery, increased hospitalization, irritability, and increased cost of care (Cheng, Cheng A. \& Tang 2010). Kuzu, Ergin \& Zencir (2006) argued that $40 \%$ of patients reported no request for staffing services (Kuzu, Ergin \& Zencir 2006). The literature lacks studies addressing compliance with the CPR by the staff to precisely determine the areas with deficiencies and provide relevant solutions (Kahouei et al. 2003).

Medical students encounter numerous educational opportunities during their studies where ethical decisionmaking is important. While considering their educational needs, students should also respect the patients' rights (Khodamoradi et al. 2016). Instituting ethical codes among students and informing them about their future careers is a critical responsibility of universities and professors (Larijani \& Zahedi 2005). Medical university students are directly in contact with patients; therefore, they need to be aware of and respect their rights, like other medical staff (Vivian et al. 2011).

Overall, the awareness level of the healthcare workers about the patients' rights is not very satisfactory, i.e. rooted in their inappropriate academic education and the lack of institutionalization of these ethical principles; it may be due to the inadequate training provided during this course. Students are directly in contact with patients during their internship in hospitals; thus, it is necessary to respect patients' rights as part of the treatment. This is because satisfaction is among the hallmarks of effective hospital services, and respecting the patients' rights is a prerequisite for achieving their satisfaction (Akbari et al. 2015). The present study aimed to evaluate the awareness level of Ahvaz Jundishapur University of Medical Sciences students of patients' clinical rights.

\section{Materials and Methods}

This descriptive-analytical study aimed to examine students' knowledge of patients' clinical rights at Ahvaz
Jundishapur University of Medical Sciences. The study population consisted of senior undergraduates, last-year students of doctor of medicine programs, and last-year $\mathrm{PhD}$ students.

They had been in contact with patients for some time during their studies. This was to ensure that the students invited to the investigation have sufficient contact with patients. The necessary authorization was obtained from the Research Vice-Chancellor of the university. Next, the required data were collected from students involved in clinical settings at day and night shifts (i.e. those studying Nursing, Midwifery, Surgical technology, Anesthesiology, Medicine, Dentistry, \& Rehabilitation Sciences). The inclusion criteria were a history of clinical attendance as an extern or intern, the ability to answer questions, and willingness to participate in research. The study subjects were assured their achieved data would remain confidential. The sample size was calculated to be 223 , considering $0.05 \%$ attrition rate using the following Formula:

$$
\begin{aligned}
& \begin{array}{l}
1 . n=\left(Z 1-\frac{a}{2}+Z 1-\beta\right) 2 \times(\delta 02+\delta 12) /(\mu 0-\mu 1) \\
\mu 0=13.37 \mu 1=15.07 \quad \delta 0=4.05 \quad \delta 1=3.57 \quad Z 1-\alpha / 2=1.96 \\
\alpha=0.05 Z 1-\beta=1.64
\end{array}
\end{aligned}
$$$$
B=0.2 N=223
$$

The required data were collected by a cluster sampling technique for each faculty. Then, in each faculty, sampling was randomly conducted by the researchers.

A two-section questionnaire was used for data collection. The first section covered demographic items, including gender, academic program, and the field of study. The second section contained 29 multiple-choice questions about the 5 principles of the CPR in Iran (including 4 questions about access to services, 8 questions about informed consent, 6 questions about personal freedom, 6 questions about patient's awareness of the treatment process, and 5 questions about confidentiality). To determine the awareness level, each correct answer to each item was given one score (minimum: 0, maximum: 29) (Yaghobian et al. 2014).

To determine the awareness level, scores between 0-9 were considered as poor awareness, $10-19$ as moderate, and 20-29 as good. The questionnaire had been previously used in domestic studies, and its validity and reliability were measured and approved. Arab and Ranjbar computed the reliability of this questionnaire as $r=0.83$. Besides, another study using the test-retest method documented 
Table 1. Students' demographic characteristics

\begin{tabular}{|c|c|c|}
\hline \multicolumn{2}{|l|}{ Demographic Variables } & No. (\%) \\
\hline \multirow{2}{*}{ Gender } & $\mathrm{F}$ & $103(51)$ \\
\hline & M & $97(48)$ \\
\hline \multirow{2}{*}{ Educational level } & BSc. & $149(74)$ \\
\hline & PhD & $51(25)$ \\
\hline \multirow{6}{*}{ Faculty } & $\begin{array}{l}\text { Nursing and Mid- } \\
\text { wifery }\end{array}$ & $53(26)$ \\
\hline & Medicine & $45(22)$ \\
\hline & Dentistry & $15(7)$ \\
\hline & Allied Health Sciences & $22(11)$ \\
\hline & Health Sciences & $29(14)$ \\
\hline & $\begin{array}{l}\text { Rehabilitation } \\
\text { Sciences }\end{array}$ & $36(18)$ \\
\hline \multirow{2}{*}{ Were you aware of the CPR before or at the time of your internship? } & Yes & $52(26)$ \\
\hline & No & $14874)$ \\
\hline \multirow{3}{*}{ If yes, what was your source of information? } & Teacher & $50(20)$ \\
\hline & Book & $0(0)$ \\
\hline & Article & $0(0)$ \\
\hline \multirow{2}{*}{$\begin{array}{l}\text { Was the content of the university curricula appropriate to promote } \\
\text { awareness about the CPR? }\end{array}$} & Yes & $60(30)$ \\
\hline & No & $140(70)$ \\
\hline
\end{tabular}

a correlation coefficient $>0.86$ for it (Bathaei \& Asayesh 2012; Ranjbar, Zargar \& Dehghani 2010). Descriptive statistics were used for data analysis in SPSS. Moreover, the Independent Samples t-test was used for the gender-wise comparison of students' awareness level. Analysis of Variance (ANOVA) was also used to compare the awareness level of students from different faculties. In the case of nonnormality, equivalent nonparametric tests were used.

\section{Results}

Of the 223 distributed questionnaires, 200 were completed, of which $103(51 \%)$ were completed by female samples. The Mean \pm SD age of students was $21 \pm 1$ years, with the lowest and highest age being 18 and 31 years, respectively. The respondents included 149 undergraduates and $51 \mathrm{PhD}$, students. Additionally, the highest frequency (26\%) of study participants belonged to the School of Nursing and Midwifery. Only $26 \%$ of the students stated being aware of the CPR prior to the commencement of their clinical courses, and 20\% of these participants became aware of it by their university professors. The majority of students $(70 \%)$ claimed that the content of the university curriculum was ineffective in promoting students' awareness of patient rights (Table 1).
The Mean \pm SD of the 29 items of the questionnaire was $14.50 \pm 2.3$, which indicates an average level of awareness in the studied samples. The awareness level of most individuals in the dimensions of personal freedom, informed consent, individual satisfaction, awareness of the treatment process, and confidentiality of information was moderate; it was good only in terms of access to services. The highest average score belonged to the domain of access to services, whereas the lowest was in the domain of confidentiality (Table 2). The faculty-level mean scores of awareness of the CPR are presented in Table 3. These values were not significantly different across faculties $(\mathrm{P}=0.359)$ (Table 4).

\section{Discussion}

The current study aimed to evaluate the awareness level of senior students of Ahvaz Jundishapur University of Medical Sciences about the CPR. Respecting patients' rights is among the key components of providing ethical care. A tremendous body of literature is available on this issue, and numerous bylaws have been drafted accordingly; however, these efforts are insufficient to protect these rights, and measures must be taken to improve its compliance in various sectors (Zandiyeh et al. 2015). Most topics taught in medical ethics courses evolve the ethical issues 
Table 2. The students' awareness scores about the different domains of CPR

\begin{tabular}{ccccc}
\hline \multirow{2}{*}{ Domains of CPR } & \multicolumn{1}{c}{ No. (\%) } & Mean \pm SD \\
\cline { 2 - 4 } & Good & Moderate & Poor & \\
\hline Informed consent & $96(48)$ & $104(52)$ & $0(0)$ & $19.24 \pm 2.73$ \\
\hline Personal freedom & $1(0.5)$ & $174(87)$ & $25(12.5)$ & $16.48 \pm 2.28$ \\
\hline Awareness of the treatment process & $(94.5)$ & $179(89.5)$ & $12(6)$ & $14.29 \pm 2.91$ \\
\hline Confidentiality of information & $0(0)$ & $177(88.5)$ & $23(11.5)$ & $26.60 \pm 4.9$ \\
\hline Access to services & $0(0)$ & $149(76)$ & $51(24)$ & $11.78 \pm 1.91$ \\
\hline
\end{tabular}

Client- Centered Nursing Care

Table 3. Faculty-specific awareness level of students on CPR

\begin{tabular}{cccc} 
& \multicolumn{3}{c}{ Awareness Level of CPR } \\
\cline { 2 - 4 } Faculty & No. (\%) & Total \\
\cline { 2 - 4 } & Moderate & Poor & 53 \\
\hline Nursing \& Midwifery & $45(84.9)$ & $8(15.1)$ & 45 \\
\hline Medicine & $32(71.1)$ & $13(28.9)$ & 15 \\
\hline Dentistry & $11(73.3)$ & $4(26.7)$ & 29 \\
\hline Health Sciences & $19(65.5)$ & $10(34.5)$ & 36 \\
\hline Rehabilitation Sciences & $24(66.7)$ & $12(33.3)$ & $3(13.6)$ \\
\hline Allied Health Sciences & $19(86.4)$ & & 22 \\
\hline
\end{tabular}

Client- Centered Nursing Care

Table 4. Comparing students' awareness of CPR based on different faculties of Ahvaz Jundishapur University of Medical Sciences

\begin{tabular}{cccc}
\hline Awareness level & No. & Mean \pm SD & P \\
\hline Poor & 50 & $28.3 \pm 0.61$ & 0.359 \\
Moderate & 150 & $01.3 \pm 8.1$ & \\
Good & 0 & $0 \pm 0$ & \\
\hline
\end{tabular}

healthcare professionals may face in their career as well as the ethical issues concerning patient's rights usually remain unnoticed. Studies indicated that students in various medical sciences, during their studies, frequently witness unethical actions by health staff or are sometimes in a situation where they are compelled to take such actions (Dyrbye, Thomas \& Shanafelt 2005; Weaver \& Wilson 2011; Jeffrey et al. 2011). Therefore, it is crucial for medical students to know about patients' rights.

According to our findings, $75 \%$ and $25 \%$ of the students had a moderate and low level of awareness about the CPR, respectively. Similarly, another study suggested that $81 \%$ of students had moderate awareness about the CPR (Karimyar Jahromi, Hojat \& Karami 2015). Other studies revealed that $>50 \%$ of students had poor knowledge of CPR, i.e. in line with the present study data (Ranjbar, Zargar \& Dehghani 2010; Rezaei et al. 2014). A study examined nurses' views on the provisions of the CPR and indicated that nurses' views were unsatisfactory (Nasiriani, Farnia \& Nasiriani F. 2007). Another study in Pakistan reported poor knowledge of surgical team members about patients' rights and medical 
ethics (Vaskooei Eshkevari et al. 2009). A study found that the majority of medical and nursing students were well aware of the laws regarding patients' rights, i.e. inconsistent with the present study results (Yaghoubian et al. 2014). Another study demonstrated that patients' and medical staff's knowledge of CPR was good, but that compliance was not optimal (Bassiri Moghadam et al. 2011). Some studies have revealed that nurses' attitude toward respecting patients' rights (Parsapoor et al. 2009) as well as their performance (Sookhak et al. 2019) is unsatisfactory. Parsinia also stated that nurses' awareness of the CPR is low (Parsinia, Goodarzi \& Babaii 2008).

An efficient healthcare system requires active engagement and appropriate interaction between the recipients and providers of health services. Health service providers must represent an institution that understands and respects the rights and responsibilities of the recipient, their families, physicians, and other caregivers; thus, a better understanding of patient rights and an awareness of what constitutes a patient's right is required (Parsapoor, Salari \& Larijani 2013). Most studies in this area indicated that the knowledge level of the students, as well as different medical staff about the patient's rights, was unsatisfactory. Inadequate levels of student awareness in most dimensions of the CPR could ultimately lead to students' disregard for patients' rights, at school, and at the beginning of their professional careers. Consequently, it could cause numerous problems for the patient, and their dissatisfaction will result in decreased efficiency and effectiveness of hospitals and healthcare providers (Kalroozi, Dadgari \& Zareiyan 2010).

What appears to be the main cause of this problem is lacking specific courses or credits in the student's curriculum (Bathaei \& Asayesh, 2012). A research evaluated the knowledge and practice of 134 medical assistants and students in Semnan Medical University and indicated a significant relationship between performance, training, and awareness (Kahouei et al. 2003). Educating the medical staff on practical ethics to familiarize them with the patient's rights and the need for more adherence to the treatment team will promote the quality of care and patients' satisfaction (Kalroozi, Dadgari \& Zareiyan 2010). Inadequate attention to this matter in health centers and the lack of precise and accurate evaluation criteria are the main reasons for aggravating this condition.

Another reason for the low level of students' awareness could be the students' overemphasis on passing scores rather than learning and applying what they have learned from courses, including professional ethics and legal issues (Aizawa 2007; Chan et al. 2009). The insufficient or lack of training to increase students' awareness about patients' rights is another reason for unawareness in this field (Eckles et al. 2005). The conflict between the priorities of medical education and patient care and patient respect is another problem in the clinical education process (Saito et al. 2011). In this study, the highest mean score of knowledge was related to "access to services," and the lowest was associated with "confidentiality." In other research on medical students, the highest and lowest levels of knowledge belonged to "personal freedom" and "right to access to healthcare," respectively (Ranjbar, Zargar \& Dehghani 2010).

The obtained data revealed that the knowledge level of students majoring in different fields of studies about the CPR is not optimal. It is important to note that while the drafting and notification of the CPR is a valuable step in enforcing patient rights, this is not the sufficient condition. The sufficient conditions will be met only by creating awareness in relevant stakeholders, particularly students of medicine and allied medical sciences, creating an appropriate culture, paying full attention to the rights of all stakeholders, identifying the existing barriers, developing guidelines for implementing the charter, and including patients' rights among the evaluation criteria of health service providers (Karimyar Jahromi, Hojat \& Karami 2015).

Despite the importance of clinical education and the involvement of clinical students in the treatment of patients, it may not be directly beneficial to patients. It may sometimes even harm the patients or put them at a disadvantage. Therefore, the way patients should be treated in university hospitals and how to observe their rights within clinical settings needs to be carefully scrutinized. Educational hospitals should also set practical rules for medical students and related departments to protect the patient's rights and interests while not impairing the medical education process. Based on the results of this study and similar research, it is recommended to include a course or at least part of a course on the CPR in the students' curriculum and to present comprehensive and authoritative educational pamphlets and seminars for a better familiarity with patients' rights at the beginning of the internship period. Additionally, professors and clinical educators need to adhere to the provisions of the $\mathrm{CPR}$, which could be effective in advancing therapeutic and educational goals.

\section{Ethical Considerations}

\section{Compliance with ethical guidelines}

This article was extracted from a research project approved by the Ethics Committee of Jundishapur Univer- 
sity of Medical Sciences, Ahvaz, on Feb 7, 2017 (Code: IR.Ajums.REC.1395.721). The Authors adhered to codes of ethics and received their informed consent of the students.

\section{Funding}

This research did not receive any specific grant from funding agencies in the public, commercial, or not-forprofit sectors.

\section{Authors' contributions}

Conceptualization: Hadis Ashrafizadeh, Nasrin Elahi, and Shahram Molavynejad; Methodology: Hadis Ashrafizadeh, Nasrin Elahi, Shahram Molavynejad, and Mohammad Adineh; Data collection: Safa Najafi; Writing-original draft: Hadis Ashrafizadeh, Mohammad Adineh; Writing review \& editing: Hadis Ashrafizadeh, Mohammad Adineh, and Mahmood Maniati.

\section{Conflict of interest}

The authors declared no conflicts of interest.

\section{Acknowledgments}

The researchers express their gratitude to the ViceChancellor for Research and Technology of Jundishapur University of Medical Sciences, Ahvaz, for providing the necessary credentials for the present study, and they extend their gratitude to the students participating in the study.

\section{References}

Aizawa, Y., 2007. [Education of courtesy and respect (Japanese)] Medical Education, 38, pp. 268-9.

Akbari, L., et al. 2015. [Evaluation of the observance of patients' rights in the selected hospitals of Isfahan University of Medical Sciences (Persian)]. Medical Law Journal, 9(33), pp. 175-96. http:/ /ijmedicallaw.ir/browse.php?a_id=326\&sid=1\&slc_ lang=en

Arab, M. \& Zareei, A., 2009. [Patient rights: Knowledge of managers of private hospitals (Persian)]. Payesh, 8(1), pp. 25-30. http:/ / payeshjournal.ir/article-1-630-fa.html

Babamahmoodi, F., et al. 2011. [Observation of patient's right charter in Mazandaran teaching hospitals: Patients view (Persian)]. Iranian Journal of Medical Ethics and History of Medicine, 4(4), pp. 37-44. http://ijme.tums.ac.ir/browse.php?a id $=165 \&$ sid $=1 \&$ slc_lang $=$ en
Bassiri Moghadam, K., et al. 2011. [Health provider and patients awareness on patient bill of rights ind its observing rate in an educational hospital in Gonabad (Persian)]. Journal of Gonabad University of Medical Science, 17(2), pp. 45-54. http:// hms.gmu. ac.ir $/$ browse.php?a_id=1083\&sid=1\&slc_lang=fa

Bateni, M. R., Sajadi, Z. \& Hoseini M., 2011. [Patients knowledge about patients rights legislation (Persian)]. Health Information Management, 7(4), pp. 485-9. https:/ / www.sid.ir/fa/journal/ ViewPaper.aspx?id=128828

Bathaei, A. \& Asayesh, H., 2012. [Medical students' awareness of patients' rights in Qom university of medical sciences and health services (2010) (Persian)]. Iranian Journal of Medical Education, 12(5), pp. 347-55. http://ijme.mui.ac.ir/article1-1767-en.html

Chan, M., et al. 2009. Smart homes-current features and future perspectives. Maturitas, 64(2), pp. 90-7. [DOI:10.1016/j.matutl ritas.2009.07.014] [PMID]

Cheng, M. M., Cheng, A. Y. N. \& Tang S. Y. F., 2010. Closing the gap between the theory and practice of teaching: Implications for teacher education programmes in Hong Kong. Journal of Education for Teaching, 36(1), pp. 91-104. [DOI:10.1080/02607470903462222]

Dyrbye, L, N., Thomas, M. R. \& Shanafelt T. D., 2005. Medical student distress: Causes, consequences, and proposed solutions. Mayo Clinic Proceedings, 80(12), pp. 1613-22. [DOI:10.4065/80.12.1613] [PMID]

Eckles, R. E., et al. 2005. Medical ethics education: where are we? Where should we be going? A review. Academic Medicine, 80(12), pp. 1143-52. [DOI:10.1097/00001888-200512000-00020] [PMID]

Hooshmand, A., et al. 2007. [Nurses' information and their view points about patient's rights and practical facilitators in clinics (Persian)]. Journal of Hayat, 12(4), pp. 57-66. http:/ / hayat. tums.ac.ir/browse.php?a_id=196\&sid=1\&slc_lang=en

Jeffrey, J., et al. 2011. Effects of international health electives on medical student learning and career choice. Family Medicine, 43(1), pp. 21-8. [PMID]

Jolaee, S., Nikbakht Nasrabadi, A. R. \& Parsa Yekta, Z, 2005 [The view of patients and patients' companions regarding patients' rights: A phenomenological research (Persian)]. Journal of Hayat, 10(4), pp. 5-20. http://hayat.tums.ac.ir/browse php?a_id=244\&sid=1\&slc_lang=en

Joolaee, S. \& Hajibabaee, F., 2012. Patient rights in Iran: A review article. Nursing Ethics, 19(1), pp. 45-57. [DOI:10.1177/0969733011412100] [PMID]

Kahouei, M., et al. 2003. [Medical assistants and students knowledge and practice rate regarding documentation of care provided to patients from medical discipline aspect (Semnan Medical University; 2000-2001) (Persian)]. Journal of Babol University of Medical Sciences, 5(2), pp. 62-73. https://www.sid.ir/ en/journal/ViewPaper.aspx?id=25647

Kalroozi, F., Dadgari, F. \& Zareiyan, A., 2010. Patients' satisfaction with patient's bill of right observance. Iranian Journal of Military Medicine Fall, 12(3), pp. 143-8. http:// militarymedj.ir/browse.php?a_code=A-10-517-1\&slc_ lang $=$ en\&sid $=1 \& \mathrm{sw}=$ Satisfaction

Khodamoradi, K., et al., 2016. [A survey on knowledge of baccalaureate and master degree nursing students of patient rights 
(Persian)]. Medical Ethics Journal, 4(12), pp. 133-48. http://journals.sbmu.ac.ir/en-me/article/view/12880/9754

Kuzu, N., Ergin, A. \& Zencir, M., 2006. Patients' awareness of their rights in a developing country. Public Health, 120(4), pp. 290-6. [DOI:10.1016/j.puhe.2005.10.014] [PMID]

Larijani, B., Ghafourifard, S. \& Zahedi, F., 2005. [Ethical considerations in clinical education of medical students (Persian)] Iranian Journal of Diabetes and Metabolism, 4, pp. 105-9. http:/ / ijdld.tums.ac.ir $/$ browse.php?a_id=5055\&sid=1\&slc_lang=en

Larijani, B. \& Zahedi, F., 2005. [Medicine and modern medical ethics (Persian)]. Iranian Journal of Diabetes and Metabolism, 4, pp. 1-11. http://ijdld.tums.ac.ir/browse.php?a id $=5046 \&$ sid $=1 \&$ slc_lang $=$ en

Karimyar Jahromi, M., Hojat, M. \& Karami, Z., 2015. [Evaluation students 'awareness of patients' rights in clinical students of Jahrom Medical University (Persian)]. Iranian Journal Of Nursing Research, 10(3), pp. 1-10. https://www.sid.ir/en/Journal/ ViewPaper.aspx?ID=458752

Mastaneh, Z. \& Mouseli, L., 2013. Patients' awareness of their rights: insight from a developing country. International Journal Of Health Policy And Management, 1(2), pp. 143-6. [DOI:10.15171/ijhpm.2013.26] [PMID] [PMCID]

Nasiriani, KH., Farnia, F. \& Nasiriani, F., 2007. [Study of respecting patients rights from nurses point of view employed in Yazd hospitals (Persian)]. Scientific Journal Of Forensic Medicine, 13(1), pp. 33-7. http://sjfm.ir/browse.php?a $\mathrm{id}=50 \&$ sid $=1 \&$ slc_lang $=\mathrm{en}$

Ozdemir, M. H., et al .2009. Midwives and nurses awareness of patients' rights. Midwifery, 25(6), pp. 756-65. [DOI:10.1016/j. midw.2008.01.010] [PMID]

Parsapoor, A. R., Salari, P. \& Larijani, B., 2013. Implementation of patient's rights charter: A report from Ministry of Health and Medical Education, Iran. Iranian Journal Of Public Health, 42(Supple1), pp. 9-12. [PMID] [PMCID]

Parsapoor, A., et al. 2009. [The necessity of observing patients right: surveying patients', physicians' and nurses' attitudes around it (Persian)]. Medical Ethics and History of Medicine, 2(4) pp. 79-90. http://ijme.tums.ac.ir/article-1-266-fa.html

Parsinia, M., Goodarzi, M. \& Babaii, G., 2008. [Investigating the level of awareness of nurses working in hospitals in Karaj about patient rightss (Persian)]. Journal of Urmia Nursing And Midwifery Faculty, 5(2), pp. 2-6. http://unmf.umsu.ac.ir/article-1-35-fa.htm

Ranjbar, M., Sameyeh Zargar, A. \& Dehghani, A., 2010. [Students' awareness of patients' right in teaching hospitals of Yazd (Persian)]. Medical Ethics and History of Medicine, 3(4), pp. 51-60. http:/ /ijme.tums.ac.ir/article-1-215-en.html

Rezaei, J., et al. 2014. [The knowledge and attitudes of nursing and midwifery students of Kermanshah University of Medical Sciences in conjunction with the need to respect the patients' bill of rights, 2012 (Persian)]. Journal Of Clinical Research In Paramedical Sciences, 3(1), pp. 32-9. https://www.sid.ir/en/ journal/ViewPaper.aspx?id=497902

Saito, Y., et al. 2011. Building medical ethics education to improve Japanese medical students' attitudes toward respecting patients' rights. The Tohoku Journal of Experimental Medicine, 224(4), pp. 307-15. [DOI:10.1620/tjem.224.307] [PMID]
Sookhak, F, et al. 2019. Nurses' level of awareness and observance of patients' rights. Journal of Client-Centered Nursing Care, 5(3), pp. 167-74. [DOI:10.32598/JCCNC.5.3.167]

Vaskooei Eshkevari, KH., et al. 2009. [The assessment of observing patients' right in Tehran University of Medical Sciences' hospitals (Persian)]. Iranian Journal of Medical Ethics and History of Medicine, 2(4), pp. 47-54. http://ijme.tums.ac.ir/article1-263-en.html

Vivian, LMH., et al. 2011. Medical students' experiences of professional lapses and patient rights abuses in a South African health sciences faculty. Academic Medicine, 86(10), pp. 1282-7. [DOI:10.1097/ACM.0b013e31822be4b8] [PMID]

Weaver, R. \& Wilson, I., 2011. Australian medical students' perceptions of professionalism and ethics in medical television programs. BMC Medical Education, 11, p. 50 . [DOI:10.1186/1472-6920-11-50] [PMID] [PMCID]

Yaghobian, M., et al. 2014. Association between awareness of patient rights and patient's education, seeing bill, and age: A cross-sectional study. Global Journal of Health Science, 6(3), pp. 55-64. [DOI:10.5539/gihs.v6n3p55]

Zandiyeh, M., et al. 2015. [Quality of compliance of patient's rights in operating rooms of Hamadan's educational hospitals in 2012 (Persian)]. Pajouhan Scientific Journal, 13(2), pp. 21-31. http:// psj.umsha.ac.ir/browse.php?a_code=A-10-50-2\&slc lang=en\&sid $=1$ 